\section{EaD Colaborativa no SUS: uma proposta da Comunidade de Práticas para os trabalhadores da Saúde}

Recibido: 1 Julio 2015 - Revisado: 30 Septiembre 2015

Aceptado: 30 Octubre 2015 - Publicado: 30 Diciembre 2015

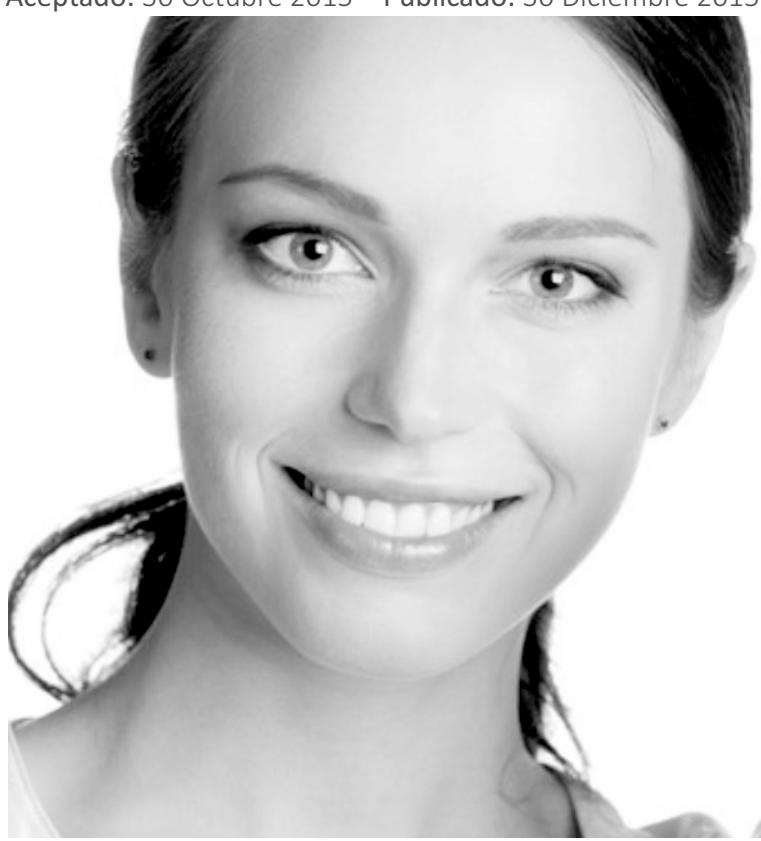

Thiago Petra

Comunidade de Práticas - Ministério da Saúde, Governo Federal | thiago.petra@saude.gov.br

Fernanda Marcolino

Comunidade de Práticas - Ministério da Saúde Governo Federal. / fernanda.marcolino@saude.gov.br

\section{Aline Corso}

Comunidade de Práticas - Ministério da Saúde, Governo Federal. | aline.corso@gmail.com

\section{Felipe Cavalcanti}

Departamento de Gestão da Educação na Saúde/SGTES/MinSaúde, Governo Federal felipe.cavalcanti@saude.gov.br

Resumo: No âmbito da formação pedagógica dos trabalhadores da saúde pública observamos que, a partir do universo de possibilidades advindas das novas tecnologias de comunicação e informação, ainda há dificuldades existentes no desenvolvimento de novas abordagens educacionais ou no uso dinâmico e potente destas tecnologias. Partindo de uma discussão acerca dos conceitos de inteligência coletiva (LÉVY, 2007), colaboração (VIGOTSKY, 1999; PIAGET, 1970) e aprendizagem colaborativa (DILLENBOURG, 1999), o presente artigo visa discorrer sobre o projeto Comunidade de Práticas (CdP) do Ministério da Saúde como ambiente virtual que agrega possibilidades de construção coletiva e colaborativa do conhecimento, e realiza um estudo de caso a partir da avaliação dos cursos disponibilizados.

Abstract: Under the context of pedagogical training of public health workers it is noticed that, from the universe of possibilities arising from new technologies of communication and information, there are still difficulties in developing new educational approaches or dynamic and powerful use of these technologies. Starting from a discussion of the concepts of collective intelligence (LÉVY, 2007), collaboration (VIGOTSKY, 1999; PIAGET, 1970) and collaborative learning (DILLENBOURG, 1999), this article aims to discuss the Comunidade de Práticas project (CdP) of Brazil's Ministry of Health as virtual environment that brings collective and collaborative possibilities of knowledge growth, and undertake a case study based on the evaluation of available courses.

Key Words: education; health; community of practices; collaborative learning. 


\section{INTRODUÇÃO}

Assim como todos os campos do conhecimento e de prática profissional, a saúde possui críticas relevantes à práxis pedagógica na formação de seus trabalhadores. Paulo Freire aponta para um obstáculo comum nos dias atuais, ao apresentar a prática bancária tradicional nas salas de aula, para a qual a Educação seria o ato de depositar, transferir e reproduzir valores e conhecimentos para seres em adaptação e ajustamento, passivos, ingênuos, acríticos e desprovidos de um poder criador mínimo (FREIRE, 1987; COTTA et al., 2012). E, se ele não viveu o bastante para presenciar o universo de possibilidades advindas das tecnologias de informação e comunicação contemporâneas, percebemos a dificuldade que existe no desenvolvimento de novas abordagens pedagógicas ou no uso dinâmico e potente destas tecnologias.

Esta concepção de educação centralizadora vem se modificando com o estabelecimento da relação sujeito-sujeito na participação dos profissionais de saúde em ambientes de interação, principalmente os virtuais. Nesse sentido, os processos de aprendizagem a distância podem ser uma oportunidade para compor uma nova e profícua relação com base em uma prática pedagógica dialógica. Segundo Lévy (2007), a internet assumiria o papel de via essencial de troca, intercâmbio, interrelações, interação e construção do conhecimento; tornando-se um instrumento para a facilitação da emergência de um pensamento coletivo, que viria acompanhado da correlata sensação de se pertencer à famosa "aldeia global".

Como podemos ver, há a necessidade em tornar a proposta pedagógica mais social e interessante ao aluno. Para isso, podemos contemplar ações para estimular a interação e a colaboração, seja através do uso de novas tecnologias ou de metodologias pedagógicas. A plataforma Moodle $e^{1}$ tem se mostrado uma ferramenta potente para diversas propostas de aprendizagem, mas há a constatação de que existe uma manutenção do modelo tradicional de educação, mesmo sendo à distância, e que envolve questões de narrativas e linguagens dos conteúdos, a participação da tutoria, o uso simplório das ferramentas do próprio Moodle, entre outros.

Ao desenvolver um ambiente de cursos específico para uma plataforma que fortalece uma cultura de rede social, o projeto Comunidade de Práticas (CdP) se insere numa nova perspectiva colaborativa e interativa na educação.

\section{EAD COLABORATIVA}

Quando Pierre Lévy (2001, p. 11-18) aponta que a colaboração será a solução para o excesso de informação, o filósofo está inserido num contexto em que a internet traz o que ele chama de "dilúvio da informação". Este dilúvio não teria refluxo, pois o volume de informações gerado pela nossa sociedade ultrapassou a capacidade de ser gerenciada individualmente, como acontecia nos tempos das enciclopédias. Quanto mais um indivíduo interagir com o outro, mais estará apto a reconhecer comportamentos, intenções, valores, competências que compõem seu meio (COSTA, 2000), o que seria essencial para a construção do conhecimento de forma colaborativa.

Pierre Lévy contribui para esta discussão por apresentar uma face da realidade, mesmo que virtual, em que estamos inseridos. Porém, durante os séculos XX e XXI vimos (e estamos vendo) reflexões sobre as

\footnotetext{
1 Moodle (Modular Object Oriented Distance Learning) é um sistema de

1 Moodle (Modular Object Oriented Distance Learning) é um sistema de
gerenciamento para criação de cursos online. Como uma espécie de sala de aula virtual, o aluno tem acesso a conteúdos disponibilizados pelos professores, participa de fóruns de discussão, envia trabalhos, etc.
} 
abordagens de aprendizagem que se desenvolveram até chegarmos nas diversas maneiras de se construir um curso à distância. Vamos partir da reflexão do educador Oreste Preti (2002), que traz o Empirismo, o Inatismo e a Dialética como teorias que influenciaram o pensamento e a prática pedagógica na modernidade.

Segundo o Empirismo, o conhecimento se dá na leitura da realidade via sentidos; o processo de ensinar e aprender é centrado na figura do professor, que, detentor do conhecimento que acumulou ao longo de sua experiência (tempos), esforça-se para que o aluno domine determinados conteúdos que são considerados corretos para um ideal de sociedade (ou sociedade ideal). Ele organiza e define estratégias que "são eficientes" para o aluno internalizar (através da cópia, repetição, memorização, acúmulo de informação isolada, o não questionamento, hierarquia na relação).

Não é preciso repetir que esta abordagem teórica é muito comum na EAD ${ }^{2}$. Em muitos casos, podemos ver cursos com exercícios padrões, que estão ali para avaliar o conhecimento do aluno, que, no caso, seria a capacidade de memorização. A distância e a abertura para classes mais numerosas, para muitos professores/conteudistas, são problemas para acompanhar até que ponto o aluno acumulou o conhecimento ali imposto (independente de qual narrativa ou tecnologia).

Já pelo Inatismo, o conhecimento seria intelectual, provindo das ideias e não da experiência. Na aprendizagem aqui proposta, rejeita-se o sensorial e se privilegia a razão como caminho para se chegar ao conhecimento. No discurso hipotético "o Homem já traz, ao nascer, uma herança genética (pacote de conhecimento), que poderá ser aberto e atualizado".

\footnotetext{
2 Sigla para Educação a Distância. Designa uma forma de ensinoaprendizado onde o professor e o aluno, estando em espaços físicos distintos, têm uma aula em ambiente virtual, proporcionada por tecnologias específicas. A principal característica da EAD é a flexibilização dos horários.
}

Diferente da teoria empirista, o foco passa ser o aluno, por sua capacidade inata de apreender - é de responsabilidade do sujeito a aprendizagem ou não. Instituição, escola ou professor têm a função de criar condições para despertar e apoiar o aluno.

Tradicionalmente, em cursos EAD autoinstrucionais não se estimula a interação com tutor ou com aluno, pois o individualismo é premiado. Aqui há um grande engano, uma vez que a figura do professor é preterida, mesmo que a construção do conhecimento dependa de um planejamento realizado com sucesso.

Por último, temos a teoria Dialética, uma alternativa de superação às outras duas, pois rejeita o absolutismo de um dos polos da relação professoraluno. Aqui é importante buscar e estimular uma síntese das duas posições. É um processo de ir e vir, de reflexão-ação, de interação da experiência sensorial e da razão.

O conhecimento é uma "construção humana de significados que procura fazer sentido do seu mundo" (JONASSEN, 1996). A aprendizagem depende das condições do aluno como das condições do ambiente, de quem aprende e de que educa, dos estudantes como da instituição. E claro, este conhecimento não é transmitido ou adquirido.

Com base na teoria dialética e na reflexão de Pierre Lévy, precisamos definir o que seria essa construção do conhecimento de forma colaborativa. O termo precisa ser decomposto para ser plenamente compreendido. Conhecimento, conhecer, seria assimilar completamente e experiencialmente um dado ou informação. Desde a década de 1930, com Vigotsky (1999; 2001) e, posteriormente com Piaget (1970), compreende-se que o conhecimento não é assimilado ou absorvido, mas construído dentro do 
ser que associaria as informações e estímulos recebidos do ambiente com sua própria experiência de vida em um processo contínuo e retroalimentado de construção. Ambos afirmam que a aprendizagem seria um processo social que depende, exclusivamente, do acesso que o aprendiz teria à informação e do grupo social no qual está inserido.

Finalmente o termo "colaborativo" para aprendizagem colaborativa, sugere que haja um agrupamento de pessoas que tragam suas experiências, acessos, conhecimento pessoal para trocar com outros do grupo trabalhando intencionalmente pela aprendizagem de todos ou colaborando. Nos termos de Vigotsky (1999) essa seria uma aprendizagem social intencional. Nas concepções atuais, do mundo altamente conectado, a reunião deste grupo não se daria apenas em uma sala de aula ou espaço físico, mas em um ambiente eletrônico que pudesse ser acessado por qualquer pessoa a qualquer hora através de aparelhos (devices) fixos ou móveis.

A definição simples de aprendizagem colaborativa pode ser vista por Dillenbourg (1999), "uma situação de aprendizagem na qual duas ou mais pessoas aprendem ou tentam aprender juntas". Por mais que seja simples, essa noção geral pode ser interpretada de várias maneiras, levando em consideração questões como: número mínimo ou máximo de pessoas nessa relação; o que significa "aprender algo"; aprender juntos presencial ou virtual, síncrona ou assíncrona, esforço junto ou com divisão de tarefas. "Assim sendo, a prática de aprendizagem colaborativa pode assumir múltiplas caracterizações, podendo haver dinâmicas e resultados de aprendizagem diferentes para cada contexto específico" (DILLENBOURG, 1999).

De maneira mais clara, podemos ver em Santos (2003) esta metodologia de aprendizagem colaborativa apoiada por computadores e ambientes virtuais de aprendizagem, que leva em consideração a distância entre os aprendizes. Para ela, alguns aspectos devem ser levados em consideração quando se adota esta abordagem em uma plataforma virtual:

- Criar sites hipertextuais que agreguem: intertextualidade, intratextualidade, multivocalidade, navegabilidade, mixagem, integração de várias linguagens, integração de vários suportes midiáticos.

- Potencializar comunicação interativa síncrona e assíncrona.

- Criar atividades de pesquisa que estimulem a construção do conhecimento partindo de situações-problema.

- Criar ambientes em que os saberes sejam construídos num processo comunicativo relacional e nos quais a tomada de decisões seja compartilhada.

- Disponibilizar e incentivar conexões lúdicas, artísticas e navegações fluídas;

A existência de muitas iniciativas virtuais voltadas à educação em saúde não reflete a uma avaliação da aprendizagem colaborativa sendo explorada para saúde. Como vimos, a tecnologia pode apoiar uma metodologia voltada a prática educativa que explora a colaboração. Mas é preciso, como desafio, fugir do tecnicismo. Outro ponto importante são as especificidades da educação em saúde, como veremos a seguir.

\section{EDUCAÇÃO NASAÚDE}

Na formação básica dos profissionais de saúde, em sua maioria, falta o desenvolvimento para lidar com a subjetividade e a diversidade cultural das pessoas, além das habilidades necessárias para trabalhar de 
forma integrada em equipe e enfrentar questões como a organização da assistência à saúde, a implementação dos princípios do Sistema único de Saúde (SUS), o direito universal à saúde e à informação, a necessidade de ampliar a autonomia das pessoas e de lidar com questões sociais e comportamentais (CARDOSO, 2012).

Segundo Peduzzi (2009), estudos apontam a fragilidade do impacto das capacitações na qualidade dos serviços de saúde. Nesse sentido, destaca-se a implantação da Educação Permanente em Saúde (EPS) como política nacional para formação e desenvolvimento de trabalhadores da saúde, tendo em vista a articulação entre as possibilidades de desenvolver a educação dos profissionais e a ampliação da capacidade resolutiva dos serviços de saúde. Os trabalhadores da saúde precisam buscar e acessar constantes espaços de reflexão sobre a prática, a atualização técnico-científica e o diálogo com usuários/população e demais trabalhadores que integram os serviços (PEDUZZI, 2009).

É necessário aproximar a educação da vida cotidiana, como fruto do reconhecimento do potencial educativo da situação de trabalho, ou seja, no trabalho também se aprende. Para se produzir mudança nas práticas nos serviços de saúde é preciso analisar reflexivamente os problemas da prática, valorizar o próprio processo de trabalho no seu contexto intrínseco, privilegiar o conhecimento prático em suas ações educativas e favorecer a reflexão compartilhada e sistemática (DAVINI, 2009).

Sobre a EPS, Ceccim (2005) acrescenta que há necessidade de descentralizar e disseminar capacidade pedagógica entre os trabalhadores da saúde, entre os gestores de ações, serviços e sistemas de saúde; em uma ação nos permitiria constituir o Sistema Único de Saúde verdadeiramente como uma rede-escola.
Aqui atingimos a compreensão inicial da nossa situação. Temos uma população dispersa, com diversas experiências no trabalho com grande potencial educativo, ávida por conhecimento em saúde e que podemos construir as possibilidades de atingi-los de forma minimamente danosa e conforme suas necessidades e realidade, de forma a auxiliar e orientar seu desenvolvimento pessoal e profissional por meio da construção de um ambiente que favoreça a aprendizagem colaborativa e a cidadania.

Para haver mudança nas práticas de saúde, é preciso uma mudança de paradigmas de uma educação tradicional para uma educação que favoreça a inovação, colabore para a formação de um profissional crítico que possa atender as necessidades reais da população (FERREIRA et al., 2008), e o caminho do questionamento e da crítica na prática que envolva a autoria e o domínio do aprendiz sobre seu processo de aprendizagem se coloca como uma das diretrizes do projeto Comunidade de Práticas.

\section{COMUNIDADE DE PRÁTICAS: FACILITADORES E AMBIENTE DE COLABORAÇÃO}

Com a necessidade de inserir uma proposta pedagógica em uma prática social em rede para uma educação permanente em saúde, o projeto Comunidade de Práticas $(\mathrm{CdP})^{3}$ disponibiliza o ambiente de EAD que agrega possibilidades de construção coletiva e colaborativa que um site de rede social tem o potencial de oferecer.

Para uma aprendizagem colaborativa, a escolha (ou desenvolvimento) da(s) tecnologia(s) precisa se centrar na interação social e na colaboração. E, se tratando da saúde, o ambiente precisa integrar as experiências dos usuários (na vida, na internet, no social) em vários contextos, conjugado aos novos paradigmas da web. O desafio seria empoderar aquele que aprende.

\footnotetext{
${ }^{3}$ Site oficial https://atencaobasica.org.br Acesso em 22 de junho de 2015.
} 
Se o foco está naquele que aprende e no seu contato com o grupo social, faz-se necessário viabilizar um ambiente de fácil e múltiplo acesso que disponibilize ferramentas/recursos que possibilitem controle e liberdade na construção do conhecimento. E neste sentido, o projeto Comunidade de Práticas partiu de algumas questões essenciais para o formato de uma plataforma social e de processos de aprendizagem colaborativa:

Comunicação e cooperação: o ambiente precisa oferecer possibilidades para que o aprendiz possa se comunicar de maneira distribuída um-um e todostodos, sem necessariamente seguir a hierarquia imposta pelos fóruns de $\mathrm{AVAs}^{4}$; partilhar sua produção da maneira que preferir e apoiar/participar do processo de outros aprendizes. A rede pode permitir o debate e a colaboração e estes serão estimulados pelos aprendizes sob orientação mútua;

Gestão de informação: é necessário permitir ao aprendiz que ele agregue informação e conhecimento, analise a informação para adquirir/construir conhecimento. Filtrar, conectar, categorizar, gravar/memorizar, sintetizar, compartilhar, a partir de suas necessidades;

Gestão/produção de conteúdo: Viabilizar condições para que o usuário apresente suas opiniões de diversas formas. Que ele possa manipular seu conteúdo, remisturar (remix) e adaptar para construção do conhecimento ou da comunicação, o que está intimamente relacionado com o conceito de recursos educacionais abertos $(\mathrm{REA})^{5}$.

Gestão de aprendizado: permitir que o usuário module e siga o seu aprendizado a partir da sua

${ }^{4}$ Sigla para Ambiente Virtual de Aprendizagem. É o local virtual onde cursos a distância são disponibilizados. Exemplo: Moodle.

${ }^{5}$ Conforme a declaração de Paris sobre Recursos Educacionais Abertos (2012), "REA são materiais de ensino, aprendizagem e investigação em quaisquer suportes, digitais ou outros, que se situem no domínio público ou que tenham sido divulgados sob licença aberta que permite acesso, uso, adaptação e redistribuição gratuitos por terceiros, mediante nenhuma restrição ou poucasrestrições". Ver http://www.rea.net.br/site/conceito Acesso em 22 de junho de 2015. motivação e das suas necessidades, perfazendo um caminho singular, que pode não ser linear. Espera-se que isso permita um ambiente favorável ao desenvolvimento da aprendizagem em adultos (andragogia), pois é fundamental que o conteúdo tenha um significado e uma necessidade pessoal ao aprendiz, em consonância com os conceitos de metodologias ativas de ensino-aprendizagem, aprendizagem de adultos e aprendizagem significativa.

Neste sentido, a Comunidade de Práticas elaborou um ambiente específico de cursos de cursos de Educação à Distância (EAD), cuja modelagem se baseia nos paradigmas da Inteligência Coletiva e da Educação Permanente em Saúde. Deste modo, o ambiente virtual de aprendizagem proposto valoriza a interação entre os participantes, permitindo colocar em contato práticas e modos no exercício da profissão na Atenção Básica, de maneira a favorecer a troca de afetos, experiências e conhecimentos que realmente incidam nas formas de produção do cuidado.

Neste ambiente, a proposta é que o curso seja coinstrucional. Como vimos em Orestes (2002), para uma aprendizagem colaborativa é preciso que haja uma abordagem dialética e é preciso valorizar a interação entre os alunos, com apoio do material didático. Neste sentido, a Comunidade de Práticas desenvolveu uma estrutura que permite a valorização da contribuição do aluno. O material é disponibilizado e, em cada apresentação, há o espaço de interação assíncrona. Não há um fórum isolado do que é discutido, e as interações são diferentes em cada material disponibilizado. Outro ponto estimulado é a abertura dos cursos. Com licença Creative Commons ${ }^{6}$ , a CdP permite que o aluno possa baixar e replicar em outros ambientes, podendo modificá-lo, com base no movimento REA (Recursos Educacionais Abertos). Por último, o aluno tem a autonomia de participar do

\footnotetext{
${ }^{6}$ A Comunidade de Práticas está licenciada com uma Licença Creative Commons - Atribuição-NãoComercial-Compartilha Igual 4.0 Internacional..
} 
curso conforme seu tempo. Enquanto uns realizam todo o processo (se levar em consideração o contato com o material deste ambiente) em poucos dias, outros podem acessar este ambiente em meses. Não há uma motivação para a linearidade do curso, o que podemos considerar como uma experimentação de abertura e autonomia não tão comuns nos cursos tradicionais e outras plataformas consideradas inovadoras (no MOOC Coursera7, há um período definido de participação, com início e fim, para certificação).

Como curso coinstrucional, o aluno é o sujeito de sua aprendizagem e cria redes com outros alunos e o próprio ambiente. É possível, por exemplo, participar de uma discussão no curso e levá-la para uma comunidade ou um relato de experiência, outros ambientes de interação da Comunidade de Práticas. Para estimular o protagonismo do aluno (ou da comunidade) e o acesso a outros espaços, existe a figura do facilitador, como veremos mais a frente.

Mas é importante frisar que em todo o seu contexto, com ambientes de comunidades, perfis sociais, ambiente para compartilhar relatos de experiência e um chat público, o ambiente de curso é mais uma oferta de aprendizagem. Assim como se explora a interação, a colaboração e o compartilhamento de práticas dos trabalhadores, a Comunidade de Práticas também se coloca a frente de uma discussão de educação problematizadora e conectada.

\section{ESTUDO DE CASO: AVALIAÇÃO DOS CURSOS DA CDP}

O primeiro curso da CdP foi lançado em fevereiro de 2014 e, até junho de 2015, há seis curso abertos com temáticas envolvendo as práticas integrativas e complementares e as doenças crônicas, com

${ }^{7}$ Ver https://pt.coursera.org Acesso em 22 de junho de 2015 conteúdos elaborados por áreas técnicas do Ministério da Saúde ${ }^{8}$.

Os cursos possuem características discutidas anteriormente, ou seja, são coinstrucionais, abertos, sem turmas definidas e sem a presença do tutor. Nessa metodologia, existe a pessoa designada para o papel de facilitador, que não é o de tutor nem de professor, comum nos modelos tradicionais de ensino. Seu papel essencial não é o de ensinar ou responder as dúvidas sobre o conteúdo técnico apresentado aos participantes/educandos do curso, mas de auxiliá-los no uso da metodologia proposta com suas ferramentas, além de incentivá-los a trocar experiências e conhecimentos sobre as temáticas apresentadas, de uma forma horizontal, promovendo o protagonismo do aluno e da rede. O facilitador exercendo uma mediação colaborativa, não ocupando o papel central ou de liderança/referência, potencializando a interação e a produção do conhecimento coletivo. DIAS (2008) explica que este papel de mediação colaborativa induz a comunidade a ter uma liderança partilhada, o que dá autonomia aos participantes dela. Eles são os responsáveis pelo processo de construção da interação.

Esse modelo inovador, aberto e dialógico, nos apresenta como desafio a baixa taxa de concluintes. No conjunto de todos os cursos, a Comunidade de Práticas teve 15.205 participantes (até o dia 17 de junho de 2015) e média de $14,02 \%$ de concluintes. Estes números são apenas uma "fotografia" dentro de uma lógica aberta de educação onde os alunos possuem liberdade para acessar os cursos sem ser de maneira linear (podendo acessar, por exemplo, o último módulo, em vez do primeiro), de baixar o material e replicar em seus ambientes, de realizarem

\footnotetext{
${ }^{8}$ Os cursos, oferecidos gratuitamente, são: Autocuidado: como apoiar a pessoa com diabetes (nível agente comunitário de saúde, médio e superior), Doenças crônicas nas redes de atenção à saúde, Uso de plantas medicinais e fitoterápicos para agentes comunitários de saúde, Tratamento do tabagismo e Gestão de práticas integrativas e complementares. O curso Facilitação: promovendo interação em ambientes de aprendizagem colaborativa entrará no ar em 15 de julho de 2015
} 
o curso em períodos assíncronos. Entretanto, entre os concluintes a avaliação se revela positiva e pode ser evidenciada nos comentários registrados.

A proposta para o desenvolvimento do conteúdo dos cursos é que seja elaborado e realizado por uma equipe multiprofissional, com vistas à construção de uma aprendizagem integrada e contextualizada com a realidade do aprendiz e com um viés de busca da aplicação prática e da interdisciplinaridade. Considerando que a aprendizagem significativa se refere à construção de sentidos para o objeto do conhecimento; e que para ser significativo, o conteúdo deve relacionar-se aos conteúdos prévios do aluno, exigindo dele uma atitude favorável capaz de atribuir significado próprio ao conteúdo que assimila (FIGUEIREDO, 2012, p. 94), alguns relatos da avaliação mostram essa identificação e a constituição da aprendizagem significativa, como estes a seguir:

O curso foi muito proveitoso por trazer reflexões em torno da prática que vem sendo desenvolvida em minha unidade de saúde. Saio estimulada a novas ações e intervenções em minha prática e atuação profissional junto a equipe e o território." (Participante 1, curso DOENÇAS CRÕNICAS NAS REDES DE ATENÇÃO ${ }^{9}$ ) e, Esse curso me auxiliou no meu trabalho no dia-a-dia da unidade, nos atendimentos dos pacientes com diabetes, pois depois desse curso passei a orienta-los com mais precisão e a ter um olhar clínico sobre cada situação presente na unidade." (Participante 3 do curso AUTOCUIDADO: COMO APOIAR A PESSOA COM DIABETES-NÍVEL MÉDIO ${ }^{10}$ ).

Cada tema proposto dialogou de certa forma com a 'realidade', o 'conhecimento prévio' de cada um e, a partir disso, fomentou a problematização dessas situações. Certamente, o curso ampliou a

\footnotetext{
${ }^{9}$ Curso disponível em: https://cursos.atencaobasica.org.br/courses/7786 Acesso em 22 de junho de 2015.

${ }^{10}$ Curso disponível em: https://cursos.atencaobasica.org.br/courses/7784 Acesso em 22 de junho de 2015.
}

compreensão dos problemas existentes no cotidiano de trabalho e possibilitou a intervenção em muitos deles. Logo, pode-se afirmar que o curso não se restringiu a conteúdos teóricos, distantes da realidade e que não problematizasse aspectos gerenciais e de processo de trabalho das equipes.

Considerando o referencial teórico da Educação Permanente em Saúde, é imprescindível incorporar o ensino e o aprendizado ao cotidiano do trabalho, no sentido de provocar a reflexão e as mudanças nas práticas. Desse modo, é preciso formular estratégias educativas que problematizem o próprio fazer e colocar as pessoas como atores reflexivos da prática e construtores do conhecimento e de alternativas de ação, ao invés de receptores. Outro ponto importante é eleger a equipe como ponto de interação, de modo a evitar a fragmentação disciplinar (CECCIM, 2005). O reflexo na equipe está presentes nos seguintes relatos:

Confesso que estava desmotivada em relação aos grupos com os diabéticos mas agora esse curso me deu um gás para voltar a organizar os grupos novamente. Puxar a equipe para organizá-los" (Participante 4, curso AUTOCUIDADO: COMO APOIAR A PESSOA COM DIABETES - AGENTE COMUNITÁRIO DE SÁÚDE ${ }^{11}$ ); Curso maravilhoso supriu minhas expectativas. Faço parte de uma equipe de uma UBS/RS, exercendo a função de técnica de enfermagem, e juntamente com nossas três ACS fizemos um grupo de estudo todas as quintas-feiras para realizarmos esse curso. Estamos fazendo uma horta de chás nos fundos do próprio ESF." (Participante 5, curso USO DE PLANTAS MEDICINAIS E FITOTERÁPICOS PARA AGENTES COMUNITÁRIOS DE SAÚDE ${ }^{12}$ ).

\footnotetext{
${ }^{11}$ Curso disponível em: https://cursos.atencaobasica.org.br/courses/7785 Acesso em 22 de junho de 2015.

${ }^{12}$ Curso disponível em: https://cursos.atencaobasica.org.br/courses/7802 Acesso em 22 de junho de 2015.
} 
A possibilidade de troca de experiências entre os profissionais teve impacto positivo para os participantes do curso e esteve presente em algumas avaliações, evidenciando a potência da construção conjunta e o apoio entre pares.

(...) A interação na rede social sobre os relatos de experiência de cada integrante do curso me possibilitou tirar as dúvidas e os anseios de como colocar em ação no cotidiano do trabalho e até mesmo levar para outras realidades que realmente precisam conhecer novas ferramentas de trabalho para outras abordagens em tratamentos. (Participante 6, curso GESTÃO DE PRÁTICAS INTEGRATIVASE COMPLEMENTARES)

Dentre os pontos positivos do curso tem-se: a disponibilidade do horário onde cada participante tem o controle de seu tempo, os materiais disponíveis para download que vem complementar o nosso aprendizado, a interação e o envolvimento do grupo em compartilhar seus conhecimentos e realidade de trabalho, suas dificuldades e suas realizações bem como dicas valiosas de uma rotina de serviço." (Participante 7, curso USO DE PLANTAS MEDICINAIS E FITOTERÁPICOS PARA AGENTES COMUNITÁRIOS DE SAÚDE ).

Segundo Dias e Cassiani (2005), a educação a distância não mais se caracteriza pela distância, pois a virtualidade permite encontros cada vez mais efetivos que favorecem o processo ensino-aprendizagem. As tecnologias de comunicação e informação (TICs) propiciam um alto poder de interação entre os participantes, rompendo com a ideia de espaço e tempo, o que era distante pode se tornar perto. A dimensão do tempo e do espaço são instituídas a partir das necessidades, dos interesses e da vontade dos aprendizes, ampliando as possibilidades da educação. Os relatos abaixo clarificam essa dimensão de espaço e temporalidade e evidenciam a metodologia proposta pelo curso (educação à distância) como algo positivo.
Gostaria de agradecer a oportunidade de realizar o curso e dizer que fiquei muito satisfeita com esta iniciativa. Sou enfermeira de ESF e quase não tenho tempo livre, com o curso a distância e sem tempo fixo para finalizar os estudos consegui aproveitar bem os conteúdos e realmente me dedicar quanto eu conseguia um tempo disponível. (Participante 6 do curso AUTOCUIDADO: COMO APOIAR A PESSOA COM DIABETES - NÍVEL SUPERIOR ${ }^{13}$ )

Esse tipo de curso à distância veio a facilitar muito o nosso trabalho, pois resolve dúvidas e anseios que até então estava longe." (Participante 7 do curso DOENÇAS CRÔNICAS NAS REDES DE ATENÇÃO)

\section{CONSIDERAÇÕES FINAIS}

Como vimos em Santos (2003), para adotar uma abordagem colaborativa, o ambiente virtual de aprendizagem, no caso a Comunidade de Práticas, precisa seguir aspectos apresentados, como criar hipertextualidade, potencializar a comunicação interativa, criar atividade de pesquisa que estimula a construção do conhecimento, ter um ambiente em que os saberes são construídos num processo comunicativo relacional, e disponibilizar e incentivar conexões lúdicas e navegações fluídas. A partir dessas citações, podemos considerar que a Comunidade de Práticas se coloca no desafio de estimular a aprendizagem colaborativa, adotando uma abordagem significativa, dialogando com a realidade do profissional da saúde. Em cada conteúdo disponibilizado, cria um espaço de interação, que não é destacada em um fórum separado (que prevê uma síntese de todo o material disponibilizado). A interação, a troca, e a abertura do ambiente são evidenciadas pelos relatos, que revela a colaboração no processo de aprendizagem.

\footnotetext{
${ }^{13}$ Curso disponível em: https://cursos.atencaobasica.org.br/courses/7121 Acesso em 22 de junho de 2015
} 
Como uma plataforma de colaboração aberta, a abordagem pedagógica da Comunidade de Práticas incita o usuário a se colocar numa postura de responsabilidade de sua própria aprendizagem. Num formato experimental, é preciso avaliar outras questões, como esta influencia para a autonomia do trabalhador da saúde no âmbito virtual, ou dos próprios coletivos que se formam na CdP; se há, de fato, uma utilização de todas as ferramentas e espaços oferecidos; se há uma transformação do profissional em sua prática.

\section{REFERÊNCIAS BIBLIOGRÁFICAS}

Cardoso, I. M. "Rodas de educação permanente" na atenção básica de saúde: analisando contribuições. Saude soc., São Paulo , v. 21, supl. 1, p. 18-28, mai. 2012. Disponível em http://goo.gl/UZt1zo Acesso em 22 de junho de 2015.

Ceccim, R. B. Educação Permanente em Saúde: desafio ambicioso e necessário. Interface - Comunic., Saúde, Educ., v.9, n.16, p.161-77, set.2004/fev.2005.

Comunidade De Práticas. Projeto Político Pedagógico dos Cursos. Disponível em https://goo.gl/34z4Mj Acesso em 10 de junho de 2015

Costa R. Por um novo conceito de comunidade: redes sociais, comunidades pessoais, inteligência coletiva. Interface comun. saúde educ., Botucatu, v. 59, n. 17, p. 235-248, 2000. Disponível em http://goo.gl/laeeE4 Acesso em 22 de junho de 2015.

Cotta, R. M. M. et al. Construção de portfólios coletivos em currículos tradicionais: uma proposta inovadora de ensino-aprendizagem. Ciênc. saúde coletiva, Rio de Janeiro , v. 17, n. 3, p. 787-796, mar. 2012. Disponível em http://goo.gl/24CDva Acesso em 22 de junho de 2015.

Davini Mc. Enfoques, Problemas e Perspectivas na Educação Permanente dos Recursos Humanos de Saúde. In: Brasil. Ministério da Saúde. Secretaria de Gestão do Trabalho e da Educação. Política Nacional de Educação Permanente em Saúde. Brasília (DF): MS, 2009.

Dias, P. Da e-moderação à mediação colaborativa nas comunidades de aprendizagem. Educação, Formação \& Tecnologias. (2008) 1 (1). Disponível em http://goo.gl/l8FFS2 Acesso em 20 de junho de 2015.

Dias D. C; Cassiani, S. H. B. Educação de enfermagem sem distâncias - uma ruptura espaço/temporal. Rev. Esc. Enferm. USP, v.38, n.4, p.467-74, 2004. 


\section{. H.:Ingenierías}

Ferreira, M. L. S. M. et al. Construção coletiva de experiências inovadoras no processo ensinoaprendizagem na formação de profissionais da saúde. Rev. bras. educ. med., Rio de Janeiro , v. 33, n. 2, p. 240-246, jun. 2009 . Disponível em http://goo.gl/Ju686n Acesso em 22 de junho de 2015.

Figueiredo, M. D. A construção de práticas ampliadas e compartilhadas em saúde: Apoio Paidéia e formação. 2012. Tese (Doutorado em Saúde Coletiva)Faculdade de Ciências Médicas, Universidade Estadual de Campinas, Campinas.

FREIRE, P. Pedagogia do oprimido. Rio de Janeiro: Paz E Terra; 1987

Lave, Jean; Wenger, Etienne. Situated learning: legitimate peripheral participation. Cambridge: Cambridge University Press, 1991.

Lévy, P. A inteligência coletiva: por uma antropologia do ciberespaço. 5. ed. Tradução de ROUANET, L. P. São Paulo: Edições Loyola, 2007.

Pierre Lévy no Roda Viva no Roda Viva. 08 de janeiro de 2001. Entrevista (3 min 39 seg). Disponível em https://goo.gl/talQQJ Acesso em 22 de junho de 2015.

Peduzzi, M. et al. Atividades educativas de trabalhadores na atenção primária: concepções de educação permanente e de educação continuada em saúde presentes no cotidiano de Unidades Básicas de Saúde em São Paulo. Interface comun. saúde educ., Botucatu, v. 13, n. 30, p. 121-134, set. 2009. Disponível em http://goo.gl/UmJnxS Acesso em 22 de junho de 2015.

Piaget J. A construção do real na criança. Tradução de CABRAL, A. Rio de Janeiro: Zahar, 1970.

Preti, O. Bases epistemológicas e teorias em construção na Educação a Distância. Cuiabá, Liber
Livro NEAD/UFMT, 2002. Disponível em http://goo.gl/33WBzE Acesso em 22 de junho de 2015.

Vigotsky, L. S. A formação social da mente. São Paulo: Martins Fontes, 1999.

Construção do pensamento e da linguagem. São Paulo: Martins Fontes, 2001. 